\title{
Endothelial nitric oxide synthase haplotypes are associated with preeclampsia in Maya mestizo women
}

\author{
Lizbeth Díaz-Olguín $^{\mathrm{a}}$, Ramón Mauricio Coral-Vázquez ${ }^{\mathrm{b}}$, Thelma Canto-Cetinac ${ }^{\mathrm{c}}$, \\ Samuel Canizales-Quinteros ${ }^{\mathrm{d}}$, Belem Ramírez Regalado ${ }^{\mathrm{a}}$, Genny Fernández ${ }^{\mathrm{e}}$ and Patricia Canto ${ }^{\mathrm{a}, *}$ \\ ${ }^{a}$ División de Investigación Biomédica, Subdirección de Enseñanza e Investigación, Centro Médico Nacional 20 de \\ Noviembre, Instituto de Seguridad y Servicios Sociales de los Trabajadores del Estado, México, D.F., México \\ ${ }^{\mathrm{b}}$ Sección de Posgrado, Escuela Superior de Medicina, Instituto Politécnico Nacional, México, D.F., \& División de \\ Medicina Genómica, Centro Médico Nacional "20 de Noviembre”, Instituto de Seguridad y Servicios Sociales de \\ los Trabajadores del Estado, México, D.F., México \\ ${ }^{\mathrm{c}}$ Laboratorio de Biología de la Reproducción, Departamento de Salud Reproductiva y Genética, Centro de \\ Investigaciones Regionales "Dr. Hideyo Noguchi”, Mérida Yucatán, México \\ ${ }^{\mathrm{d}}$ Facultad de Química, Universidad Nacional Autónoma de México, México, D.F., México, Unidad de Biología \\ Molecular y Medicina Genómica, Instituto Nacional de Ciencias Médicas y Nutrición "Salvador Zubirán”, \\ México, D.F., Mexico \\ e Servicio Prenatal del Hospital Materno Infantil, S.S., Mérida, Yucatán, México
}

\begin{abstract}
Preeclampsia is a specific disease of pregnancy and believed to have a genetic component. The aim of this study was to investigate if three polymorphisms in $e N O S$ or their haplotypes are associated with preeclampsia in Maya mestizo women. A case-control study was performed where 127 preeclamptic patients and 263 controls were included. Genotyped and haplotypes for the $-768 \mathrm{~T} \rightarrow \mathrm{C}$, intron 4 variants, Glu298Asp of $e N O S$ were determined by PCR and real-time PCR allelic discrimination. Logistic regression analysis with adjustment for age and body mass index (BMI) was used to test for associations between genotype and preeclampsia under recessive, codominant and dominant models. Pairwise linkage disequilibrium between single nucleotide polymorphisms was calculated by direct correlation $r^{2}$, and haplotype analysis was conducted.

Women homozygous for the Asp298 allele showed an association of preeclampsia. In addition, analysis of the haplotype frequencies revealed that the -786C-4b-Asp298 haplotype was significantly more frequent in preeclamptic patients than in controls ( 0.143 vs. 0.041 , respectively; $\left.\mathrm{OR}=3.01 ; 95 \% \mathrm{CI}=1.74-5.23 ; P=2.9 \times 10^{-4}\right)$.

Despite the Asp298 genotype in a recessive model associated with the presence of preeclampsia in Maya mestizo women, we believe that in this population the -786C-4b-Asp298 haplotype is a better genetic marker.
\end{abstract}

Keywords: Preeclampsia, maya-mestizo women, polymorphisms of eNOS, eNOS haplotypes.

\section{Introduction}

Preeclampsia is a specific disease of pregnancy [1]. This syndrome occurs in $5-7 \%$ of pregnant women,

${ }^{*}$ Corresponding author: Patricia Canto, M.D., Ph.D., División de Investigación Biomédica C.M.N. 20 de Noviembre, ISSSTE, San Lorenzo No. 502, 2nd piso, Col. del Valle, Delegación Benito Juárez, C.P. 03100, México, D.F., México. Tel.: +52 55 52003513; Fax: +52 55 55754879. E-mail: ipcanto@yahoo.com.mx. although in some populations this may be increased up to three times because of various social, economic, racial, geographic and/or social factors [2]. Despite being one of the leading causes of maternal death and a major contributor of maternal and perinatal morbidity, the precise cause for this syndrome has not been completely elucidated [3].

The mechanisms causing preeclampsia are still unclear; however, endothelial activation/dysfunction is a central pathogenic feature in women with this syn- 
drome $[4,5]$. Nitric oxide (NO) induces vasodilatation, inhibits platelet aggregation, and prevents platelet adhesion to endothelial cells [6-9]. An increment of NO production has been described in normal pregnancy $[10,11]$; on the other hand, reduced NO formation has been implicated in the pathogenesis of preeclampsia $[12,13]$. The endothelial NO synthase $(e N O S)$ is the enzyme that generates NO in blood vessels and regulates vascular function, as well as playing a protective role to endothelial cells $[14,15]$.

Susceptibility to preeclampsia is believed to have a genetic component [16-18]. Several candidate genes are under investigation in relation with the development of preeclampsia, and these include the eNOS. Three polymorphisms in the eNOS gene have been associated with preeclampsia: a single-nucleotide polymorphism (SNP) in the promoter region, the $-786 \mathrm{~T} \rightarrow \mathrm{C}$ (rs2070744), a variable number of tandem repeats in intron 4 (a 27 bp-repeat), and a SNP in exon 7 (Glu298Asp, rs1799983) [19-22]. However, the results of studies seeking associations of these polymorphisms with preeclampsia have not always been consistent in different population analyses [20,23,24]. As proposed by Sandrim et al. [21], these results are probably due to only analyzing the genotypes of one polymorphism instead of assessing the association of eNOS haplotypes with preeclampsia.

Because the mestizo and amerindian populations of Mexico are genetically heterogeneous [25] and considering the putative role of polymorphisms in genetic susceptibility to preeclampsia, the principal aim of this study was to analyze the possible association between three polymorphisms in eNOS gene (as well their haplotypes) and preeclampsia in maya mestizo women.

\section{Subjects and methods}

The study was approved by the Institute's Human Research Committee of the Centro de Investigaciones Regionales "Dr. Hideyo Noguchi”. Informed consent was obtained from all patients and controls before participation in the study. One hundred twenty seven preeclamptic women (without history of preeclampsia) and 263 pregnant non-preeclamptic women (controls) were analyzed. All patients were of Maya mestizo ethnic origin, resulting from the admixture between Maya and European (Spanish) population with at least one Maya surname. All subjects lived in the state of Yucatán.
A case-control study was performed to investigate the possible association between three eNOS polymorphisms and preeclampsia. The study was conducted at the Materno-Infantil Hospital of the Secretaria de Salud from August 2002 to September 2003. This Institution is responsible for providing maternity services to lowincome women residing in Mérida, Yucatán, Mexico. All women admitted with a diagnosis of preeclampsia who agreed to participate in the study were recruited and selected consecutively according to their regular visits to this hospital. Upon each visit, blood pressure was measured in a seated position by physicians or obstetrical nurses via the auscultatory method using a mercury sphygmomanometer. Korotkoff phase V was generally used for defining diastolic blood pressure.

Clinical findings of the patients and controls were described previously [26]. Preeclampsia was defined as the development of hypertension and proteinuria ( $>$ $300 \mathrm{mg}$ urinary protein in $24 \mathrm{~h}$ ) in women with no baseline proteinuria. Hypertension was defined as systolic blood pressure $\geqslant 140 \mathrm{mmHg}$ and/or diastolic blood pressure $\geqslant 90 \mathrm{mmHg}$ measured on two consecutive occasions at least $24 \mathrm{~h}$ apart [27]. Women with previously diagnosed hypertension were excluded from the study. The control group was comprised of women with uncomplicated pregnancy admitted for natural childbirth or caesarean section, with normal length pregnancy, blood pressure $\leqslant 120 / 80 \mathrm{mmHg}$ and without proteinuria.

\subsection{Genotyping}

Peripheral blood samples were obtained from all individuals, and genomic DNA was purified as described by Kempter and Grossbadern [28]. Three eNOS gene polymorphisms were studied: the $-786 \mathrm{~T} \rightarrow \mathrm{C}$ polymorphism in the 5'-flanking region of gene (rs2070744), the variable number of tandem repeat (27 bp-repeat) polymorphisms in intron 4 and the G-894T $\rightarrow$ Glu298Asp polymorphism in exon 7 (rs1799983).

Genotypes for intron-4 polymorphism were determined by PCR. DNA was amplified by the polymerase chain reaction (PCR) in $25 \mu \mathrm{l}$ of reaction mixture containing $200 \mathrm{ng}$ of genomic DNA, $0.2 \mathrm{mM}$ dNTPs, 2.0 U of Platinum Taq DNA polymerase (Invitrogen, Life Technologies Corporation, Brazil), and $0.2 \mu \mathrm{M}$ of each specific set of intron 4 of the eNOS primers (the sequence of the primers have been described previously) [29]. Thirty cycles of PCR amplifications were performed in a Thermal Cycler (Multigene II, Labnet International Inc., USA). Except for the last, all cycles 
were $1 \mathrm{~min}$ at $96^{\circ} \mathrm{C}, 1 \mathrm{~min}$ at $59^{\circ} \mathrm{C}$, and $1 \mathrm{~min}$ at $72^{\circ} \mathrm{C}$. In the last cycle the annealing temperature was at $72^{\circ} \mathrm{C}$ for $5 \mathrm{~min}$. After amplification, PCR products were electrophoresed on $1.2 \%$ agarose gels and stained with ethidium bromide to verify the correct size of the expected fragments; the negative control in the PCR having all reagents except DNA. Two alleles were obtained when this region was amplified: "eNOSa," which was 234 base pair (bp) long and consisted of one 27-bp repeating unit and "eNOSb," which was 261-bp long and consisted of two 27-bp repeating units.

On the other hand, real-time PCR allelic discrimination TaqMan assay ( $\mathrm{AB}$ ) was used for genotyping Glu298Asp and -786T $\rightarrow$ C polymorphisms. All PCR reactions contained $10 \mathrm{ng}$ of DNA, 5.0 $\mu \mathrm{l}$ TaqMan Universal Master Mix (AB) (2X), $0.25 \mu \mathrm{l}$ primers and probes (10X) and water for a final volume of $10 \mu \mathrm{l}$, including the appropriate negative controls in all assays.

In case of the Glu298Asp polymorphism, the assay used probes and primers designed by Applied Biosystem assay-on-demand services (assay ID: C_3219460_20), whereas for the $-786 \mathrm{~T} \rightarrow$ C polymorphism the probe and primers were designed by us. Primers sequences were as follows: forward 5'-ACC AGGGCATCAAGCTCTTC-3' and reverse 3'- GCAG GTCAGCAGAGAGACTAG-3'. The probe for each allele is as follows: wild-type FAM 5'-AGGGTCAGC CAGCCAG-3' and mutant VIC 5'-AGGGTCAGCCG GCCAG-3'. Real-time PCR was performed on an ABI Prism 7500 Fast (Applied Biosystems). Conditions for Glu298Asp were $50^{\circ} \mathrm{C}$ for $2 \mathrm{~min}, 95^{\circ} \mathrm{C}$ for $10 \mathrm{~min}$, and 50 cycles of amplification $\left(92^{\circ} \mathrm{C}\right.$ for $15 \mathrm{sec}$ and $60^{\circ} \mathrm{C}$ for $\left.1.30 \mathrm{~min}\right)$. For the $-786 \mathrm{~T} \rightarrow \mathrm{C}$ polymorphism, conditions were $50^{\circ} \mathrm{C}$ for $2 \mathrm{~min}, 95^{\circ} \mathrm{C}$ for $10 \mathrm{~min}$, and 40 cycles of amplification $\left(92^{\circ} \mathrm{C}\right.$ for $15 \mathrm{sec}$ and $60^{\circ} \mathrm{C}$ for $1 \mathrm{~min})$. For each cycle, the software determined the fluorescent signal from the VIC or FAM-labeled probe (Applied Biosystems). Allelic discrimination was performed using specific primers and probes for each allele.

\subsection{Statistical analysis}

Data from the overall patient population in the study were summarized as mean \pm standard deviation in the case of quantitative variables. Deviations from HardyWeinberg equilibrium were tested using the $\chi^{2}$ test. Power calculation of $80 \%$ assuming a $10 \%$ difference in genotype percentages was estimated using the epidemiological data obtained by Duran and Couoh [30], and
Table 1

Clinical characteristics of preeclamptic women and controls

\begin{tabular}{lccc}
\hline & Preeclampsia & Controls & $\mathrm{P}$ \\
\hline$N$ & 127 & 263 & \\
Age (years) & $22.0 \pm 5.6$ & $21.59 \pm 4.5$ & 0.349 \\
BMI (kg/m $\left.{ }^{2}\right)$ & $33.5 \pm 5.4$ & $22.5 \pm 3.2$ & $<0.0001$ \\
SBP $(\mathrm{mmHg})$ & $149.6 \pm 11.4$ & $112.8 \pm 7.2$ & $<0.0001$ \\
DBP (mmHg) & $101.3 \pm 8.4$ & $76.7 \pm 5.1$ & $<0.0001$ \\
Birth weight (g) & $2318.6 \pm 408.81$ & $3085.8 \pm 404.1$ & $<0.0001$ \\
\hline
\end{tabular}

Data are means $\pm \mathrm{SD}$.

$\mathrm{BMI}=$ Body Mass Index

$\mathrm{SBP}=$ Systolic Blood Pressure

$\mathrm{DBP}=$ Diastolic Blood Pressure.

the mathematical calculation was performed according to Pértegas and Fernández [31].

Logistic regression analysis with adjustment for age and body mass index (BMI) was used to test for associations between genotype and preeclampsia under recessive, codominant and dominant models (SPSS v. 10.0, Chicago, IL). Pairwise linkage disequilibrium between SNPs was calculated by direct correlation $r^{2}$ (Haploview v. 3.2), and haplotype analysis was conducted using PHASE 2.1 software.

\section{Results}

The mean age of women with preeclampsia and control group was $22( \pm 5.6)$ and $21.59( \pm 4.5)$ years, respectively. No cases with HELLP (hemolysis, elevated liver enzymes and low platelet count) were diagnosed. As expected, women with preeclampsia showed significantly higher systolic/diastolic blood pressures and BMI compared to control women, and these differences were significant. Likewise, the birth weight was significantly different between the preeclamptic group and the control group (Table 1).

Hardy-Weinberg equilibrium test was performed for the polymorphisms under study and showed that the distribution of the observed genotypes did not differ from the expected one, in either the patient or control group $(P>0.05)$. The statistical power of the study was $89 \%$ at $P<0.05$ to detect previous associations observed in women with preeclampsia.

$-768 \mathrm{~T} \rightarrow \mathrm{C}$, variable number of tandem repeat polymorphisms in intron 4, Glu298Asp of eNOS genotype and allele frequencies are presented in Table 2. Low pairwise linkage disequilibrium was present among the polymorphisms $\left(r^{2}<0.228\right)$. Genotype and allele distributions showed no significant differences under dominant and codominant models (Table 2). However, 
Table 2

Genotype and allele frequencies of the $-768 \mathrm{~T} \rightarrow \mathrm{C}$, intron 4 variants, Glu298Asp of $e N O S$ polymorphisms in Maya mestizo women with preeclampsia

\begin{tabular}{lccc}
\hline Polymorphism & Cases $(n=127)$ & Controls $(n=263)$ & ${ }^{*}$ P value \\
\hline$-\mathbf{7 6 8 T} \rightarrow \mathbf{C}$ & & & \\
Genotype frequencies & & & \\
$T / T$ & $94(74.0)$ & $195(74.1)$ & 0.668 \\
$T / C$ & $28(22.0)$ & $61(23.2)$ & \\
$C / C$ & $5(3.9)$ & $7(2.7)$ & \\
Allele frequency & & & \\
$T$ & $216(85.0)$ & $451(85.7)$ & \\
$C$ & $38(14.9)$ & $75(14.3)$ & \\
Intron-4 & & & \\
Genotype frequencies & & & \\
$b / b$ & $110(86.6)$ & $233(88.6)$ & \\
$b / a$ & $14(11.0)$ & $26(9.9)$ & \\
$b / c$ & $1(0.8)$ & $1(0.4)$ & \\
$a / a$ & $2(1.6)$ & $3(1.1)$ & \\
Allele frequency & & & \\
$b$ & $235(92.5)$ & $493(93.7)$ & \\
$a$ & $18(7.1)$ & $32(6.1)$ & \\
$c$ & $1(0.4)$ & $1(0.2)$ & \\
Glu298Asp & & \\
Genotype frequencies & & & \\
Glu/Glu & $94(74.0)$ & $206(78.3)$ & \\
Glu/Asp & $28(22.0)$ & $55(20.9)$ & \\
Asp/Asp & $5(3.9)$ & $2(0.8)$ & \\
Allele frequency & & & \\
Glu & $216(85.0)$ & $416(88.8)$ \\
Asp & $38(14.9)$ & $59(11.2)$ & \\
\hline Note: For the number of individuals $(n)$, values in parentheses indicate per- \\
centage. & & \\
$* P$ value adjusted for maternal age and body mass index (under dominant \\
model). & & \\
& &
\end{tabular}

women homozygous for the Asp298 allele showed an association of preeclampsia (recessive model) as compared to those carrying the Glu allele (Asp298Glu and Glu298Glu genotypes), with an odds ratio $(\mathrm{OR})=5.4$ and $95 \%$ confidence interval $(\mathrm{CI})=1.02-27.9 ; P=$ 0.047 , adjusted for age and BMI. This significant association was after adjusting for age and BMI.

Furthermore, five haplotypes with a frequency higher than $5 \%$ were identified (Table 3 ). Interestingly, the haplotype frequencies showed significant differences in cases and controls $(P<0.0001)$. The analysis revealed that the -786C-4b-Asp298 haplotype was significantly more frequent in patients with preeclampsia than in controls ( 0.143 vs. 0.041 , respectively; OR $\left.3.01 ; 95 \% \mathrm{CI}=1.74-5.23 ; P=2.9 \times 10^{-4}\right)$. Moreover, 786T-4a-Glu298 was the second most common haplotype but showed no significant group differences; whereas the -786T-4b-Asp298 and -786C-4b-Glu298 haplotypes were significantly less frequent or absent in patients as compared to controls (0.004 and 0.007 vs. 0.072 and 0.060 , respectively, $P<0.0001)$.

\section{Discussion}

Preeclampsia is a complex pregnancy-specific condition involving endothelial dysfunction and activation $[2,4,5]$ and has been suggested as a potential role of NO deficiency in the pathogenesis of preeclampsia. Furthermore, several studies found a significant association among clinically important polymorphisms as well as in eNOS gene haplotypes and this syndrome [19-22], suggesting that genetic variations in this gene may predispose to this hypertensive condition of pregnancy.

In the present study we analyzed the possible association of the polymorphisms $-786 \mathrm{~T} \rightarrow \mathrm{C}$, the variable number of tandem repeat polymorphisms in intron 4 and Glu298Asp, as well as the haplotypes of eNOS gene and preeclampsia in Maya mestizo women, finding that Glu298Asp polymorphism and three haplotypes were associated with this syndrome. Interestingly, as reported [20], we found that the pairwise linkage disequilibrium among the allelic association of the three polymorphisms was low. 
Table 3

Estimated haplotype frequency distribution of the $-768 \mathrm{~T} \rightarrow \mathrm{C}$, intron 4 variants, Glu298Asp of eNOS polymorphisms in Maya mestizo women with preeclampsia

\begin{tabular}{|c|c|c|c|c|c|}
\hline \multicolumn{3}{|c|}{ Haplotypes } & \multirow[t]{2}{*}{ Cases } & \multirow[t]{2}{*}{ Controls } & \multirow[t]{2}{*}{$P$} \\
\hline$-768 \mathrm{~T} \rightarrow \mathrm{C}$ & Intron-4 & Glu298Asp & & & \\
\hline $\mathrm{T}$ & $\mathrm{b}$ & Glu & 0.776 & 0.767 & - \\
\hline $\mathrm{C}$ & $\mathrm{b}$ & Asp & 0.143 & 0.041 & $2.9 \times 10^{-4}$ \\
\hline $\mathrm{T}$ & $\mathrm{a}$ & Glu & 0.068 & 0.019 & NS \\
\hline $\mathrm{T}$ & b & Asp & 0.007 & 0.072 & $<0.0001$ \\
\hline $\mathrm{C}$ & b & Glu & 0.004 & 0.060 & $<0.0001$ \\
\hline
\end{tabular}

$P$ considered significant when $<0.008$ (0.05/haplotype number). Only haplotypes with a frequency higher than $5 \%$ in cases or controls were showed. NS, non-significant.

Serrano et al. [20] reported the association among the same three polymorphisms and haplotypes of $e N O S$ and presence of preeclampsia in women from Colombia. In accordance with our results, the main finding of their study was that women homozygous for the Asp298 allele, in addition to the presence of a high-risk -786C4b-Asp298 haplotype, were associated with preeclampsia. Noteworthy, in our population the differences of this haplotype between preeclamptic and control women was significantly higher $\left(P=2.9 \times 10^{-4}\right)$. Additionally, frequency of the same haplotype in our population was higher compared with the Colombian women with preeclampsia ( $14.3 \%$ vs. $9.3 \%$, respectively).

Likewise, Sandrim et al. [21] studied the relationship between the same polymorphisms of eNOS and Brazilian women with preeclampsia; nevertheless, there were no significant differences in genotype distribution. Albeit, they found significant differences in the distribution of the haplotype frequencies when women with preeclampsia were compared with the control group, especially the -786C-4a-Glu298 haplotype. However, this haplotype is not common in our population $(<1 \%)$. In addition, the authors found that the -786T-4a-Glu298 haplotype apparently protects against preeclampsia. In contrast, we found an inverse association where this haplotype was more frequent in cases $(6.8 \%)$ than in controls $(1.9 \%)$, although this difference was not significant.

Inconsistencies of the results in different populations regarding the association of the $-786 \mathrm{~T} \rightarrow \mathrm{C}$, variable number of tandem repeat polymorphisms in intron 4 and Glu298Asp polymorphisms of the eNOS and preeclampsia may be caused by differences in ethnic groups $[19,20,32,33]$. We have already observed this in other studies related to preeclampsia in Maya mestizo women [26,34]. For that reason, differences in the frequency and type of haplotypes described by Serrano et al. [20], Sandrim et al. [21] and in this study may be due to genetic background.

Several studies have suggested that the Glu298Asp polymorphism of $e N O S$ has functional consequences. Savvidou et al. [35] examined the vascular responses in healthy pregnancy, demonstrating that healthy pregnant women homozygous for the Asp298 polymorphism had a lower flow-mediated dilatation of the brachial artery ( $21 \%$ lower) in comparison with the women who carried the Glu298 allele in a homozygous state. Because the flow-mediated dilation is an NO-dependent response, the authors proposed that women with the Glu298Asp polymorphism may reduce the threshold for endothelial dysfunction and thus be more likely to develop preeclampsia. On the other hand, in vitro analysis of the eNOS Glu298Asp polymorphism has provided insight that in a recessive model Asp298 may affect the function of the protein because the eNOS Asp298 undergoes selective proteolytic cleavage in endothelial cells and vascular tissue, thereby reducing vascular NO generation [36,37]. However, Fairchild et al. [38] and McDonald et al. [39] reported contradicting results about the function of this polymorphism, suggesting that this observation may be due to an artifact.

Moreover, in vitro assay of $-786 \mathrm{~T} \rightarrow \mathrm{C}$ polymorphism of $e N O S$ has shown that only the $C$ allele reduces promoter activity of the eNOS gene [40,41]. In addition, subjects with the $C$ allele presented a decreased serum concentration of nitrite/nitrate [41]. Jeerooburkhan et al. [42] observed that this polymorphism does not significantly influence the plasma levels of NO. On the other hand, studies of the variable number of tandem repeats in intron 4 polymorphism of $e N O S$ indicate that carriers of this variant have lower nitric oxide plasma levels and decreased protein expression $[43,44]$, whereas other studies have shown no evidence for this findings $[42,45]$. 
Recently, Sandrim et al. [22] evaluated, for the first time, the association among plasma nitrite concentrations and three eNOS polymorphisms in Brazilian women with normal pregnancy as well as in women with preeclampsia, finding that women with normal pregnancy and the common haplotype (-786T-4bGlu298) showed a high nitrite concentration in comparison with the preeclampsia group $(P<0.004)$. These authors suggested that perhaps the last haplotype protects against the development of preeclampsia due to increased nitric oxide formation. In contrast, in our population this haplotype was similar between controls and cases (76.7\% vs. $77.6 \%$, respectively), suggesting that these differences may be due to the ethnic diversity.

It has been suggested that the haplotypes of the eNOS gene may affect response to antihypertensive treatment in women with preeclampsia [46]; nevertheless, in the population of Brazilian women the most common haplotypes that affect treatment response were -786C-4aGlu298 and -786T-4a-Asp298, which are very different from the major haplotype found in our study (786C-4b-Asp298). These findings all underline the importance of determining, in different populations, the eNOS gene haplotypes in women with preeclampsia.

\section{Acknowledgments}

This study was supported by Consejo Nacional de Ciencia y Tecnología (CONACYT), México (Grant: SALUD-2007-C01-69693) and by the Instituto Politécnico Nacional, México (Grant: 20082977/2090647).

L. Díaz-Olguín, was supported by Consejo Nacional de Ciencia y Tecnología (CONACYT) fellowship award. We thank M.A. Martínez Ramírez for technical assistance.

S. Morey, Executive Editor, Scientific Communications, assisted in the English review of the manuscript.

\section{References}

[1] J.M. Roberts and D.W. Cooper, Pathogenesis and genetics of pre-eclampsia, Lancet 357 (2001), 53-56.

[2] P. López-Jaramillo, J.P. Casas and N. Serrano, Preeclampsia: from epidemiological observations to molecular mechanisms, Braz J Med Biol Res 34 (2001), 1227-1235.

[3] K.Y. Lain and J.M. Roberts, Contemporary concepts of the pathogenesis and management of preeclampsia, JAMA 287 (2002), 3183-3186.

[4] J.M. Roberts, R.N. Taylor, T.J. Musci, G.M. Rodgers, C.A. Hubel and M.K. McLaughlin, Preeclampsia: an endothelial cell disorder, Am J Obstet Gynecol 161 (1989), 1200-1204.
[5] J.M. Roberts and C.W.G. Redman, Pre-eclampsia: more than pregnancy-induced hypertension, Lancet 341 (1993), 14471451.

[6] M.W. Radomski, R.M. Palmer and S. Moncada, Endogenous nitric oxide inhibits human platelet adhesion to vascular endothelium, Lancet 2 (1987), 1057-1058.

[7] P. Kubes, M. Suzuki and D.N. Granger, Nitric oxide: an endogenous modulator of leukocyte adhesion, Proc Natl Acad Sci USA 88 (1991), 4651-4655.

[8] V.M. Bolotina, S. Najibi, J.J. Palacino, P.J. Pagano and R.A. Cohen, Nitric oxide directly activates calcium-dependent potassium channels in vascular smooth muscle, Nature $\mathbf{3 6 8}$ (1994), 850-853.

[9] U. Forstermann and T. Munzel, Endothelial nitric oxide synthase in vascular disease: from marvel to menace, Circulation 113 (2006), 1708-1714.

[10] C.P. Weiner, R.G. Knowles and S. Moncada, Induction of nitric oxide synthases early in pregnancy, Am J Obstet Gynecol 171 (1994), 838-843.

[11] D.J. Williams, P.J. Vallance, G.H. Neild, J.A. Spencer and F.J. Imms, Nitric oxide-mediated vasodilation in human pregnancy, Am J Physiol 272 (1997), H748-H752.

[12] S.P. Seligman, J.P. Buyon, R.M. Clancy, B.K. Young and S.B. Abramson, The role of nitric oxide in the pathogenesis of preeclampsia, Am J Obstet Gynecol 171 (1994), 944-948.

[13] V.C. Sandrim, A.C. Palei, I.F. Metzger, V.A. Gomes, R.C. Cavalli and J.E. Tanus-Santos, Nitric oxide formation is inversely related to serum levels of antiangiogenic factors soluble fmslike tyrosine kinase-1 and soluble endogline in preeclampsia, Hypertension 52 (2008), 402-407.

[14] P.A. Marsden, H.H. Heng, S.W. Scherer, R.J. Stewart, A.V. Hall, X.M. Shi, L.C. Tsui and K.T. Schappert, Structure and chromosomal localization of the human constitutive endothelial nitric oxide synthase gene, J Biol Chem 268 (1993), 17478-17488.

[15] Y. Wang, Y. Gu, Y. Zhang and D.F. Lewis, Evidence of endothelial dysfunction in preeclampsia: decreased endothelial nitric oxide synthase expression is associated with increased cell permeability in endothelial cells from preeclampsia, Am J Obstet Gynecol 190 (2004), 817-824.

[16] A. Molvarec, A. Vér, A. Fekete, K. Rosta, L. Derzbach, Z. Derzsy, I. Karádi and J. Jr. Rigó, Association between estrogen receptor alpha (ESR1) gene polymorphisms and severe preeclampsia, Hypertens Res 30 (2007), 205-211.

[17] A. Molvarec, A. Jermendy, B. Nagy, M. Kovács, T. Várkonyi, P. Hupuczi, Z. Prohászka and J. Jr. Rigó, Association between tumor necrosis factor (TNF)-alpha G-308A gene polymorphism and preeclampsia complicated by severe fetal growth restriction, Clin Chim Acta 392 (2008), 52-57.

[18] K. Rosta, A. Molvarec, A. Enzsöly, B. Nagy, Z. Rónai, A. Fekete, M. Sasvári-Székely, J. Jr. Rigó and A. Vér, Association of extracellular superoxide dismutase (SOD3) Ala40Thr gene polymorphism with pre-eclampsia complicated by severe fetal growth restriction, Eur J Obstet Gynecol Reprod Biol 142 (2009), 134-138.

[19] J.E. Tanus-Santos, M. Desai and D.A. Flockhart, Effects of ethnicity on the distribution of clinically relevant endothelial nitric oxide variants, Pharmacogenetics 11 (2001), 719-725.

[20] N.C. Serrano, J.P. Casas, L.A. Díaz, C. Páez, C.M. Mesa, R. Cifuentes, A. Monterrosa, A. Bautista, E. Hawe, A.D. Hingorani, P. Vallance and P. López-Jaramillo, Endothelial NO synthase genotype and risk of preeclampsia: a multicenter case-control study, Hypertension 44 (2004), 702-707. 
[21] V.C. Sandrim, A.C. Palei, R.C. Cavalli, F.M. Araújo, E.S. Ramos, G. Duarte and J.E. Tanus-Santos, eNOS haplotypes associated with gestational hypertension or preeclampsia, Pharmacogenomics 9 (2008), 1467-1473.

[22] V.C. Sandrim, A.C Palei, J.T. Sertorio, R.C. Cavalli, G. Duarte and J.E. Tanus-Santos, Effects of eNOS polymorphisms on nitric oxide formation in healthy pregnancy and in pre-eclampsia, Mol Hum Reprod 16 (2010), 506-510.

[23] R. Landau, H.G. Xie, V. Dishy, A.J. Wood, C.M. Stein and R.M. Smiley, No association of the Asp298 variant of the endothelial nitric oxide synthase gene with preeclampsia, Am J Hypertens 17 (2004), 391-394.

[24] A. Seremak-Mrozikiewicz, K. Drews and P.M. Mrozikiewicz, The -786T/C polymorphism of the endothelial nitric oxide synthase gene in preeclampsia, Eur J Obstet Gynecol Reprod Biol 138 (2008), 118-119.

[25] R. Juárez-Velázquez, P. Canto, T. Canto-Cetina, H. RangelVillalobos, H. Rosas-Vargas, M. Rodríguez, S. CanizalesQuinteros, A.C. Velázquez Wong, R.M. Ordoñez-Razo, G. Vilchis-Dorantes and R.M. Coral-Vázquez, Analysis of polymorphisms in genes (AGT, MTHFR, GPIIIa, and GSTP1) associated with hypertension, thrombophilia and oxidative stress in Mestizo and Amerindian populations of México, Dis Markers 28 (2010), 323-331.

[26] P. Canto, T. Canto-Cetina, R. Juarez-Velazquez, H. RosasVargas, H. Rangel-Villalobos, S. Canizales-Quinteros, A.C. Velázquez-Wong, M.T. Villarreal-Molina, G. Fernández and R. Coral-Vázquez, Methylenetetrahydrofolate reductase C677T and glutathione S-transferase P1 A313G are associated with a reduced risk of preeclampsia in Maya-Mestizo women, Hypertens Res 31 (2008), 1015-1019.

[27] Report of the National High Blood Pressure Education Program Working Group on High Blood Pressure in Pregnancy, Am J Obstet Gynecol 183 (2000), S1-S22.

[28] B. Kempter and K. Grossbadern, Quick preparation of high molecular weight DNA by freezing, Trends Genet 8 (1992), 226.

[29] S.M. Roth, S.M. Williams, L. Jiang, K.S. Menon and J.J. Jeka, Susceptibility genes for gentamicin-induced vestibular dysfunction. J Vestib Res 18 (2008), 59-68.

[30] N. Duran and J. Couoh, Epidemilogía de la preeclampsiaeclampsia de una muestra en Yucatán, Ginec Obstet Mex 67 (1999), 571-577.

[31] S. Pértegas Díaz and S. Pita Fernández, Unidad de Epidemiología Clínica y Bioestadística. Complexo HospitalarioUniversitario Juan Canalejo. A Coruña (España) Cad Aten Primaria 10 (2003), 59-63.

[32] H. Rosas-Vargas, A. Flores-Segura, B. Guizada-Claure, G. Vargas-Alarcón, J. Granados, F. Salamanca and R. CoralVázquez, Endothelial nitric oxide synthase gene polymorphism in the Indian and Mestizo populations of Mexico, Hum Biol 75 (2003), 91-96.

[33] J.P. Casas, L.E. Bautista, S.E. Humphries and A.D. Hingorani, Endothelial nitric oxide synthase genotype and ischaemic heart disease: metaanalysis of 26 studies involving 23028 subjects, Circulation 109 (2004), 1359-1365.

[34] T. Canto-Cetina, S. Canizales-Quinteros, E. de la Chesnaye, R. Coral-Vázquez, J.P. Méndez and P. Canto, Analysis of C-850T and G-308A polymorphisms of the tumor necrosis factor-alpha gene in Maya-Mestizo women with preeclampsia, Hypertens Pregnancy 26 (2007), 283-291.
[35] M.D. Savvidou, P.J. Vallance, K.H. Nicolaides and A.D. Hingorani, Endothelial nitric oxide synthase gene polymorphism and maternal vascular adaptation to pregnancy, Hypertension 38 (2001), 1289-1293.

[36] M. Tesauro, W.C. Thompson, P. Rogliani, L. Qi, P.P. Chaudhary and J. Moss, Intracellular processing of endothelial nitric oxide synthase isoforms associated with differences in severity of cardiopulmonary diseases: cleavage of proteins with aspartate vs. glutamate at position 298, Proc Natl Acad Sci USA 6 (2000), 2832-2835.

[37] A. Persu, M.S. Stoenoiu, T. Messiaen, S. Davila, C. Robino, O. El-Khattabi, M. Mourad, S. Horie, O. Feron, J.L. Balligand, R. Wattiez, Y. Pirson, D. Chauveau, X.M. Lens and O. Devuyst, Modifier effect of eNOS in autosomal dominant polycystic kidney disease, Hum Mol Genet 11 (2002), 229-241.

[38] T.A. Fairchild, D. Fulton, J.T. Fontana, J.P. Gratton, T.J. McCabe and WC. Sessa, Acidic hydrolysis as a mechanism for the cleavage of the Glu(298)3Asp variant of human endothelial nitric-oxide synthase, J Biol Chem 276 (2001), 26674-26679.

[39] D.M. McDonald, N.J. Alp and K.M. Channon, Functional comparison of the endothelial nitric oxide synthase Glu298Asp polymorphic variants in human endothelial cells, Pharmacogenetics 14 (2004), 831-839.

[40] M. Nakayama, H. Yasue, M. Yoshimura, Y. Shimasaki, K. Kugiyama, H. Ogawa, T. Motoyama, Y. Saito, Y. Ogawa, Y. Miyamoto and K. Nakao, T-7863C mutation in the 5'flanking region of the endothelial nitric oxide synthase gene is associated with coronary spasm, Circulation 99 (1999), 28642870 .

[41] Y. Miyamoto, Y. Saito, M. Nakayama, Y. Shimasaki, T. Yoshimura, M. Yoshimura, M. Harada, N. Kajiyama, I. Kishimoto, K. Kuwahara, J. Hino, E. Ogawa, I. Hamanaka, S. Kamitani, N. Takahashi, R. Kawakami, K. Kangawa, H. Yasue and K. Nakao, Replication protein A1 reduces transcription of the endothelial nitric oxide synthase gene containing a -786T3C mutation associated with coronary spastic angina, Hum Mol Genet 9 (2000), 2629-2637.

[42] N. Jeerooburkhan, L.C. Jones, S. Bujac, J.A. Cooper, G.J. Miller, P. Vallance, S.E. Humphries and A.D. Hingorani, Genetic and environmental determinants of plasma nitrogen oxides and risk of ischemic heart disease, Hypertension $\mathbf{3 8}$ (2001), 1054-1061.

[43] T. Tsukada, K. Yokoyama, T. Arai, S Hara, A. Yamada, Y. Kawaguchi, T. Hosoya and J. Igari, Evidence of association of the ecNOS gene polymorphism with plasma NO metabolite levels in humans, Biochem Biophys Res Commun 245 (1998), 190-193.

[44] X.L. Wang, A.S. Sim, M.X. Wang, G.A. Murrell, B. Trudinger and J. Wang, Genotype dependent and cigarette specific effects on endothelial nitric oxide synthase gene expression and enzyme activity, FEBS Lett 471 (2000), 45-50.

[45] Y. Yoon, J. Song and S.H. Hong, Plasma nitric oxide concentrations and nitric oxide synthase gene polymorphisms in coronary artery disease, Clin Chem 46 (2000), 1626-1230.

[46] V.C. Sandrim, A.C. Palei, M.R. Luizon, T.C. Izidoro-Toledo, R.C. Cavalli and J.E. Tanus-Santos, eNOS haplotypes affect the responsiveness to antihypertensive therapy in preeclampsia but not in gestational hypertension, Pharmacogenomics $J \mathbf{1 0}$ (2010), 40-45. 


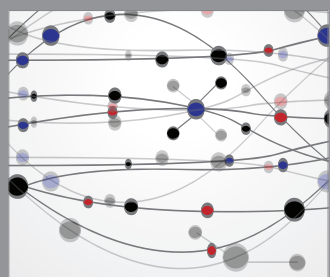

The Scientific World Journal
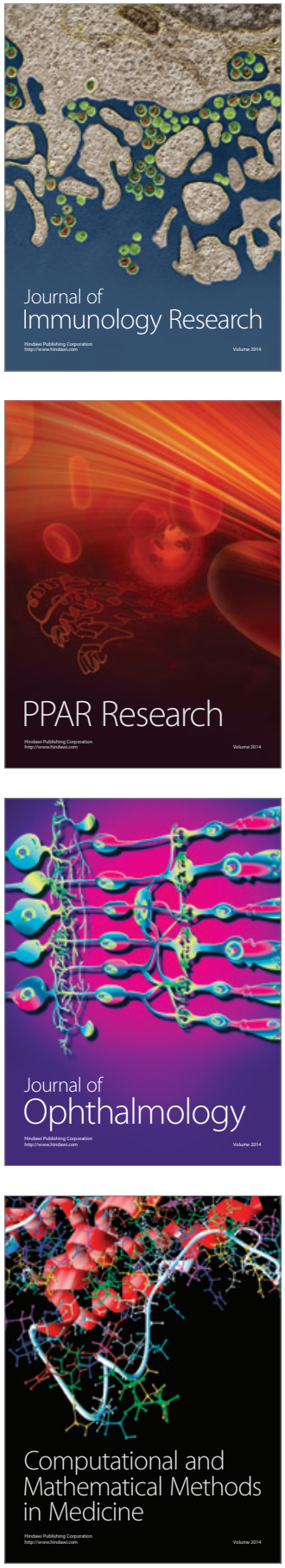

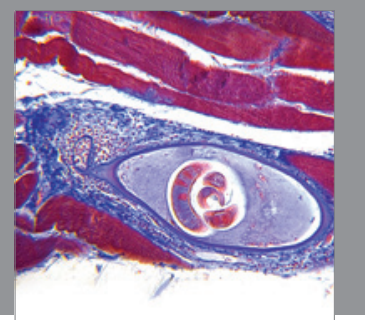

Gastroenterology

Research and Practice
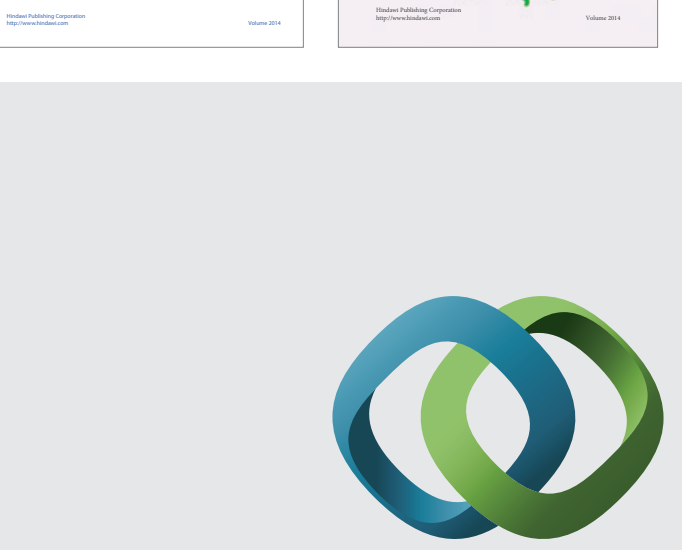

\section{Hindawi}

Submit your manuscripts at

http://www.hindawi.com
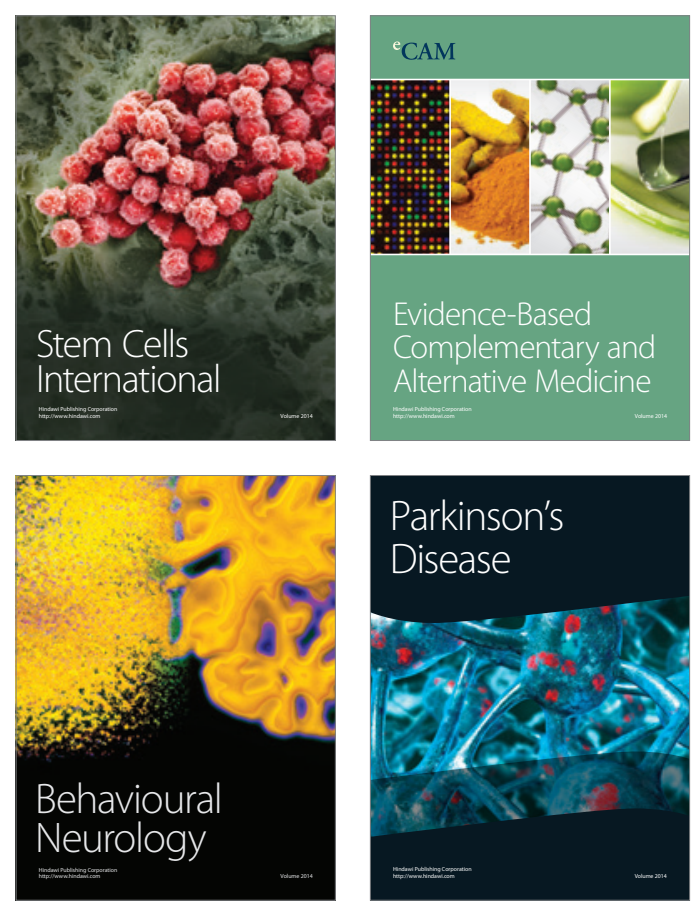

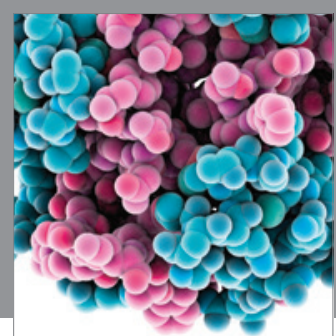

Journal of
Diabetes Research

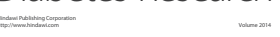

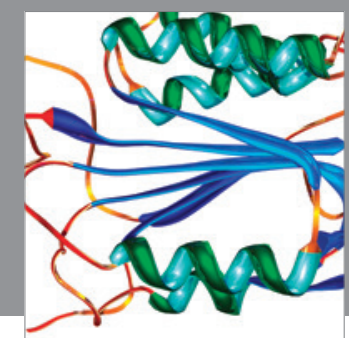

Disease Markers
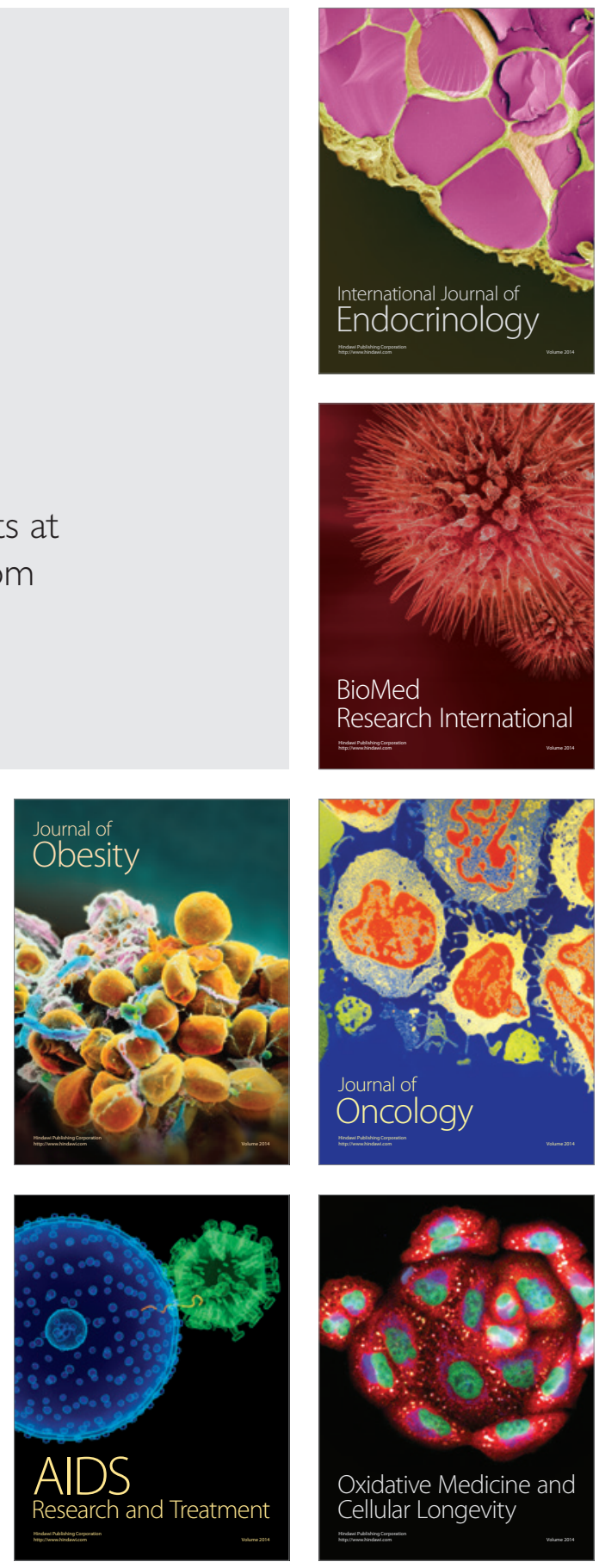